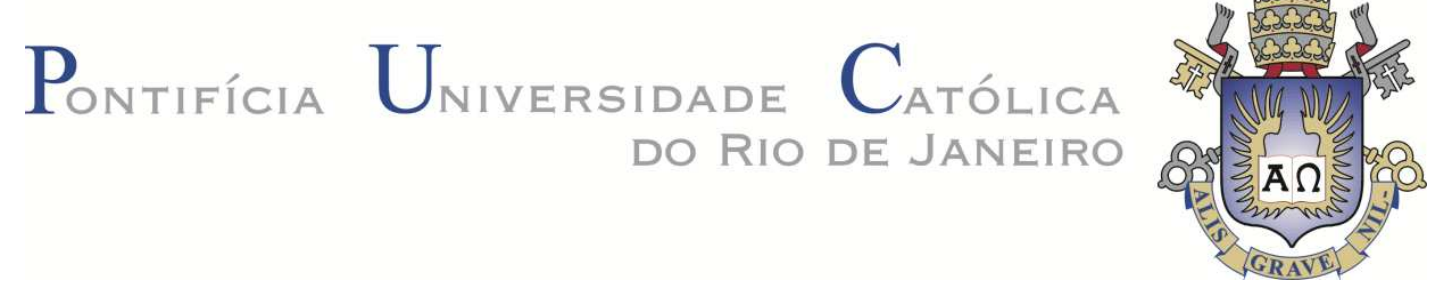

Neide Köhler Schulte

\title{
CONTRIBUIÇÕES DA ÉTICA AMBIENTAL BIOCÊNTRICA E DO VEGANISMO PARA O DESIGN DO VESTUÁRIO SUSTENTÁVEL
}

\section{Tese de Doutorado}

Tese apresentada ao Programa de Pós-graduação em Design do Departamento de Artes \& Design da PUC-Rio como parte dos requisitos parciais para obtenção do título de Doutor em Design.

Orientadora: Denise Berruezo Portinari

Rio de Janeiro

Agosto de 2011 
Neide Köhler Schulte

Contribuições da ética ambiental biocêntrica
e do veganismo para o design do vestuário
sustentável

Tese apresentada como requisito parcial para obtenção de grau de Doutor pelo Programa de Pósgraduação em Design do Departamento de Artes \& Design da PUC-Rio aprovada pela banca examinadora abaixo assinada.

Prof ${ }^{a}$ Dra Denise Berruezo Portinari Presidente/orientadora Departamento de Artes \& Design da PUC-Rio

Prof. Dr. Alfredo Jefferson de Oliveira Departamento de Artes \& Design da PUC-Rio

Prof ${ }^{\mathrm{a}}$ Dra Rita Couto Departamento de Artes \& Design da PUC-Rio

Prof. Dr. Madson Luis Gomes de Oliveira Departamento de Artes UFRJ

Prof ${ }^{\mathrm{a}}$ Dra Sandra Regina Rech Departamento de Moda da UDESC

Profa Denise Berruezo Portinari Coordenadora setorial do Centro de Teologia e Ciências Humanas-PUC-Rio 
Todos os direitos reservados. É proibida a reprodução total ou parcial do trabalho sem autorização da universidade, da autora e de orientadora.

\section{Neide Köhler Schulte}

Graduada em Desenho e Plástica com habilitação em Estamparia pela Universidade Federal de Santa Maria UFSM em 1993. Especialização em Ensino da Arte pela UNIVILLE em 1998, e em Moda: Pesquisa e Criação pela UDESC - Universidade de Santa Catarina, em 2001. Mestre em Engenharia de Produção pela UFSC Universidade de Santa Catarina, em 2003. Iniciou atividade profissional no campo da moda em 1993 e no ensino em 1997. Atualmente é professora efetiva no curso de Moda da UDESC. Tem experiência em desenho digital e moda com ênfase em sustentabilidade e ecodesign.

Ficha catalográfica

Schulte, Neide Köhler

Contribuições da ética ambiental biocêntrica e do veganismo para o design do vestuário sustentável: /Neide Köhler Schulte; orientador: Denise Berruezo Portinari. - 2011.

176f. : il (color) ; 29,7 cm

Tese (Doutorado em Artes e Design)-Pontifícia Universidade Católica do Rio de Janeiro, Rio de Janeiro, 2011.

Inclui bibliografia

1. Artes - Tese. 2. Design. 3. Moda. 4. Sustentabilidade. 5. Ética biocêntrica. 6. Veganismo. 7. Ecomoda 
Dedico este trabalho à três incríveis mulheres. Uma delas ainda pequena, mas que teve enorme paciência durante os últimos quatro anos, Sofia, minha filha. À minha mãe Nelsi, que cuidou da Sofia nas muitas horas que estive ausente, e para Elaine, que sempre me ajudou com traduções, correções e palavras de apoio. 


\section{Agradecimentos}

À minha orientadora Denise Portinari que permitiu as minhas escolhas e ajudou nos rumos da tese.

Aos demais professores a PUC-Rio e da UFSC, principalmente à querida Sônia Felipe pela aulas de Ética Prática.

Aos colegas do doutorado da UNIVILLE e da UDESC

Aos professores da banca examinadora.

Aos entrevistados veganos e à Marly Winckler, coordenadora do $12^{\circ}$ Festival Mundial Vegano.

Aos queridos amigos que compreenderam minha ausência nas festas.

À minha família, especialmente minha mãe que permitiu que eu tivesse tempo para a tese dando atenção à minha querida Sofia, que é a razão de toda a minha dedicação ao tema sustentabilidade, uma busca em ajudar a pensar e projetar uma humanidade melhor.

Aos meus queridos gatos e cães que sempre sorriram latindo ou miando quando eu tinha um minuto para dedicar a eles. 


\section{Resumo}

Schulte, Neide Köhler; Portinari, Denise Berruezo. Contribuições da ética ambiental biocêntrica e do veganismo para o design do vestuário sustentável. Rio de janeiro, 2011, p 176. Tese de doutorado. Departamento de Artes e Design. Pontifícia Universidade Católica do Rio de Janeiro.

A questão central desse estudo é verificar se os fundamentos da ética ambiental biocêntrica e a proposta do veganismo podem contribuir na reflexão sobre um sistema de moda mais pertinente à sustentabilidade ambiental e ao desenvolvimento da consciência quanto à necessidade de mudança no modo de vida dos humanos para que se preserve o ambiente natural. O pressuposto é que a proposta do veganismo e a ética ambiental biocêntrica oferecem fundamentos para um modo de produção e consumo mais adequados à sustentabilidade ambiental e para um modo de vida humana que seja menos destrutivo. Para alcançar esse objetivo levantou-se o estado da arte e os conceitos sobre moda, sustentabilidade ambiental, ética ambiental biocêntrica e veganismo; apresentou-se a proposta dos teóricos para a ética ambiental biocêntrica e estabeleceu-se uma relação com 0 estilo de vida dos veganos; entrevistou-se consumidores veganos que, segundo seu discurso, já praticam um consumo mais ético e sustentável, para verificar o seu modo de consumo; identificou-se novas propostas para o design do vestuário que visam um consumo ético e sustentável ambientalmente; e, apresentou-se a proposta do Programa de Extensão Ecomoda que vem sendo desenvolvida no curso de moda da UDESC. Esse trabalho é uma reflexão para contribuir na mudança nas engrenagens do atual sistema da moda, para que ele se torne mais adequado a uma visão de mundo mais sustentável ambientalmente.

\section{Palavras chave}

Design; sustentabilidade; ecomoda; ética biocêntrica; veganismo. 


\section{Abstract}

Schulte, Neide Köhler; Portinari, Denise Berruezo.(Advisor) Design for sustainable clothing: contibutions of biocentric environmental ethics and veganism. Rio de janeiro, 2011, p 176. Tese de doutorado. Departamento de Artes e Design. Pontifícia Universidade Católica do Rio de Janeiro.

The central question of this study is to verify that the fundamentals of biocentric environmental ethics of veganism and the proposal can contribute to reflection on a fashion system more relevant to environmental sustainability and the development of awareness of the need for change in the way of life for human to preserve the natural environment. The assumption is that the proposal of veganism biocentric environmental ethics and provide grounds for a mode of production and consumption to environmental sustainability and appropriate for a human way of life that is less destructive. To achieve this rose the state of the art and concepts about fashion, environmental sustainability, environmental ethics and biocentric veganism, presented the proposal for the theorists of biocentric environmental ethics and establish a relationship with the lifestyle of vegans; consumers interviewed are vegans who, according to his speech, already practice a more ethical and sustainable consumption, to check your mode of consumption, we identified new proposals for the design of clothing aimed at an environmentally sustainable and ethical consumption, and presented proposal to the Program Extension EcoMode being developed in the course of fashion UDESC and develop a reflection on their actions. This research is thought to contribute to a change in the gears of the current system of fashion, so that it becomes more suitable for a vision of environmentally sustainable world.

\section{Keywords}

Design, sustainability, eco-fashion, biocentric ethics, vegan. 


\section{Sumário}

1. Introdução 14

1.1 Apresentação 14

$\begin{array}{ll}1.2 \text { Questões e objetivos } & 16\end{array}$

$\begin{array}{ll}1.3 \text { Percurso metodológico } & 21\end{array}$

$\begin{array}{ll}1.4 \text { Estrutura do trabalho } & 23\end{array}$

2. O vestuário: da moda à ecomoda 25

2.1 A roupa e a moda 25

2.2 Conceitos para a moda 37

2.3 A linguagem das roupas: expressão estética e ética 41

2.4 impacto ambiental da indústria da moda e do consumismo 49

2.5 Considerações: moda, consumismo e (in) sustentabilidade 55

3 Sustentabilidade ambiental: biocentrismo, ética e veganismo 57

3.1 Sustentabilidade ambiental $\quad 57$

3.1.1 A relação (insustentável) do homem com a natureza ao longo do tempo 59

3.1.2 O design para a sustentabilidade ambiental 67

3.2 Ética ambiental biocêntrica $\quad 71$

3.3 A ética ambiental biocêntrica para resolução de conflitos 75

$\begin{array}{ll}3.4 \text { Veganismo } & 80\end{array}$

3.5 Considerações sobre sustentabilidade ambiental, ética ambiental biocêntrica e veganismo 95

4 Pesquisa de campo com veganos $\quad 99$

4.1 Metodologia da Pesquisa 99

4.1.1 A escolha da amostra e justificativa da escolha 98

4.1.2 Instrumento e técnica de análise dos resultados 100 
$\begin{array}{ll}\text { 4.1.3 Etapas e procedimentos } & 101\end{array}$

$\begin{array}{ll}\text { 4.1.4 Questionário } & 101\end{array}$

$\begin{array}{ll}\text { 4.1.5 Limitações da Pesquisa } & 103\end{array}$

$\begin{array}{ll}4.2 \text { Resultados e discussão dos resultados } & 103\end{array}$

$\begin{array}{ll}4.3 \text { Considerações sobre a pesquisa com os veganos } & 144\end{array}$

5 Propostas práticas para moda ética e sustentável 153

5.1 Programa de Extensão EcoModa UDESC 154

5.2 Algumas propostas de moda sustentável apresentadas pelas $\begin{array}{ll}\text { indústrias e marcas brasileiras } & 164\end{array}$

6 Considerações finais 172

$\begin{array}{ll}\text { 7. Referências bibliográficas e digitais } & 178\end{array}$ 


\section{Lista de figuras}

Figura 1- Desfile $1^{\circ} \mathrm{Veg}$ Fashion - em novembro de 2004

Figura 2 - Desfile da coleção "É o Bicho" - EcoModa vestindo uma nova era, no Floripa Fashion em agosto de 2005

Figura 3 - Biquíni desenvolvido com retalhos. Projeto

"modaCOMpaixão" do EcoModa em 2006

Figura 4 - Desfile "Retalhos do Brasil", Bogotá/Colômbia em 2007

Figura 5 - Oficinas de customização: roupas, acessórios

e brinquedos, 2008

Figura 6 - Desfile "EcoModa Brasil", Semana de Moda de

Bogotá/Colômbia, em 2009

Figura 7 - Coleção "Primavera Silenciosa", apresentação em

Firenze/Itália, em 2010

Figura 8 - Exposição "EcoModa" no Shopping Floripa, junho de 2011164

Figura 9 - Coleção Jeans "Caio Van Vogt" 2011 com o tecido Ecovogt 169 


\section{Lista de quadros}

Quadro 1: Dados pessoais dos entrevistados

Quadro 2: Importância e preocupação com a roupa que compra e veste

Quadro 3: Razões da importância da roupa que veste 105

Quadro 4: Tipos de roupa que mais veste 108

Quadro 5: Comentário sobre tipo de roupa que veste 108

Quadro 6: Razão para deixar de usar uma roupa e comprar outra 110

Quadro 7: Tempo de uso das roupas 111

Quadro 8: Destino das roupas que não se usa mais 113

Quadro 9: Critérios ao comprar uma roupa 114

Quadro 10: Consideração sobre a origem da roupa 116

Quadro 11: Razões para a consideração da origem da roupa 117

Quadro 12: Consideração do material que é feita a roupa 118

Quadro 13: Razões para consideração do material que é feita a roupa 118

Quadro 14: Gasto mensal com roupas 119

Quadro 15: Compra em brechó? $\quad 120$

Quadro 16: Razões para comprar ou não em brechó 120

Quadro 17: Troca roupas entre amigos e/ou familiares? 121

Quadro 18: Razões para troca ou não de roupas entre pessoas 121

Quadro 19: Aluga roupas? 122

Quadro 20: Razões para alugar ou não roupas 122

Quadro 21: Poderia comprar menos roupas? 123

Quadro 22: Comentário sobre comprar menos roupas 124

Quadro 23: Têm cuidados com a manutenção das roupas? 125

Quadro 24: Razões para cuidados com a manutenção das roupas 125

Quadro 25: Quais são os principais cuidados? 125

Quadro 26: Opinião sobre propostas diferenciadas para o vestuário 127 
Quadro 27: Conhece os princípios para a sustentabilidade sócio-ambiental?

Quadro 28: Aplica os princípios para a sustentabilidade sócio-ambiental?

Quadro 29: Exemplos de práticas sustentáveis

Quadro 30: Contribui com a sua comunidade quanto à sustentabilidade sócio-ambiental?

Quadro 31: Forma(s) de contribuição com a comunidade

Quadro 32: Opinião sobre o atual sistema da moda 